\title{
Diets Formulated on Total or Digestible Amino Acid Basis with Different Energy Levels and Physical form on Broiler Performance
}

\section{Author(s)}

Maiorka A

Dahlke $F^{1}$

Penz $\mathrm{AM}^{2}$

Kessler $\mathrm{AM}^{2}$

Universidade Federal do Paraná

2 Universidade Federal do Rio Grande do Sul

\section{Mail Address}

\section{Alex Maiorka}

Universidade Federal do Paraná

Departamento de Zootecnia

Rua dos Funcionários, 1540

80035-050. Curitiba, PR, Brasil

Email: amaiorka@ufpr.br

\section{Keywords}

digestible aminoacid, energy, ideal protein, pellet.

\section{ABSTRACT}

We studied the effects of two different systems of expressing amino acid requirements (total - TAA or digestible - DAA), two energy levels $(2,900$ or $3,200 \mathrm{kcal}$ of $\mathrm{ME} / \mathrm{kg}$ ) and two physical forms (mash or pellet) on the performance of male broilers from 21 to $42 \mathrm{~d}$ of age. Diets formulated on DAA basis improved feed conversion $(p<0.001)$ and the conversion of consumed ME into body weight gain $(p<0.001)$. Birds fed $3,200 \mathrm{kcal} \mathrm{ME} / \mathrm{kg}$ presented better feed conversion $(p<0.001)$, higher abdominal fat deposition $(p<0.001)$ and worse conversion of consumed ME into body weight gain $(p<0.001)$ as compared to birds fed 2,900 $\mathrm{kcal} \mathrm{ME} / \mathrm{kg}$. Birds fed pelleted feed had higher feed intake $(p<0.001)$, higher weight gain $(p<0.001)$, better feed conversion $(p<0.001)$, better conversion of consumed ME into body weight gain $(p<0.001)$ and higher abdominal fat deposition $(p<0.001)$. The results obtained in the present study suggest that feed formulation based on DAA is required when diets contain protein sources which amino acid digestibility is unreliable. Besides, pelleted feed improves performance parameters of broilers.

\section{INTRODUCTION}

Recent studies show the importance of diet formulation based on digestible amino acids (DAA), as well as amino acid balance, on optimal performance and reduction of environment contamination due to better use of diet protein and lower nitrogen levels in the excreta (Baker \& Han, 1994; Rostagno et al., 1995). The wide variation in the composition and amount of protein and/or amino acids present in animal byproducts is of great concern when using these raw materials. Protein and amino acid digestibility in animal byproducts primarily depend on processing temperature, cooking time and drying process, which vary according to the processing system that is used.

The excess of energy consumed by birds is deposited as fat (Rosebrough \& Steele, 1985). Excessive energy intake is related to the calorie:protein $(C: P)$ ratio in the diet, and consequently, to carcass composition. Isocaloric diets with decreasing protein levels show increasing $C: P$ ratio, which result in carcasses with higher fat percentage (Donaldson, 1985; Rosebrough \& Steele, 1985).

Pelleted feeds may especially favor the intake of birds, as birds might have difficulty picking up food if finely ground diets are provided. Several other benefits in terms of broiler performance are also attributed to pelleting, such as the improvement in the digestibility of some nutrients (Moran, 1987).

This study aimed at evaluating the live performance and carcass composition of broilers fed diets formulated on total (TAA) or digestible amino acid (DAA) basis, two energy levels $(2,900$ or 3,200 kcal $/ \mathrm{kg})$ and two physical forms (mash or pellet). 


\section{MATERIALS AND METHODS}

Four hundred Ross male chicks ( 21 to 42 days old) were used in the experiment. During the starter phase (1 to 18 days of age), chicks were housed in a commercial broiler house and fed according to the requirements proposed by NRC (1994). Feed and water were supplied ad libitum. At 18 days of age, birds were individually weighed, selected by weight and transferred to a room equipped with metabolic cages, measuring $80 \times 35 \mathrm{~cm}$. The broilers were submitted to a 3-day period of acclimation to the new environment because they have been transferred from a house with wood-shavings as litter material to wired-floor cages. Water and feed were also supplied ad libitum. Light was provided continuously throughout the experimental period.

It was evaluated two systems of expressing amino acid requirements (TAA and DAA) in the ratio recommended by Baker \& Han (1994) for ideal protein for broilers, two energy levels $(2,900$ or 3,200 kcal ME/ $\mathrm{kg}$ of diet) and two physical forms (mash or pellet). Amino acid levels in the ingredients were obtained by high-pressure liquid chromatography. TAA levels were then multiplied by their respective digestibility coefficients to determine digestibility, as suggested by Heartland Lysine (1995). Therefore, the following treatments were applied:

T1 - Diet formulation based on TAA, with 2,900 kcal of $\mathrm{ME} / \mathrm{kg}$ (mash).

T2- Diet formulation based on DAA, with 2,900 kcal of ME/kg (mash).

T3- Diet formulation based on TAA, with 2,900 kcal of $\mathrm{ME} / \mathrm{kg}$ (pellet).

T4- Diet formulation based on DAA, with 2,900 kcal of ME/kg (pellet).

T5- Diet formulation based on TAA, with 3,200 kcal of $\mathrm{ME} / \mathrm{kg}$ (mash).

T6 - Diet formulation based on DAA, with 3,200 kcal of ME/kg (mash).

T7- Diet formulation based on TAA, with 3,200 kcal of $\mathrm{ME} / \mathrm{kg}$ (pellet).

T8- Diet formulation based on DAA, with 3,200 kcal of $\mathrm{ME} / \mathrm{kg}$ (pellet).

Diets were formulated based on corn, soybean meal, meat meal, wheat bran and feather meal (Table 1).

During the experimental period, feed intake, weight gain, feed conversion and efficiency of utilization of ME (ME intake (kcal)/weight gain (g)) were measured.
Carcass quality was evaluated at the end of the experimental period (42 days of age) in 2 birds per repetition. These birds were weighed, killed, defeathered, eviscerated, and parts were weighed to obtain carcass weight (including head and feet) and abdominal fat weight. Carcass yield was determined as the carcass weight relative to body weight and expressed as percentage of body weight. Abdominal fat was expressed as percentage of carcass weight."

\begin{tabular}{|c|c|c|c|c|}
\hline Ingredients (\%) & $\mathrm{T} 1 / \mathrm{T} 3$ & $\mathrm{~T} 2 / \mathrm{T} 4$ & T5/T7 & T6/T8 \\
\hline Yellow corn & 61.61 & 61.61 & 61.61 & 61.61 \\
\hline Soybean meal 44 & 15.29 & 15.29 & 15.29 & 15.29 \\
\hline Meat meal & 5.00 & 5.00 & 5.00 & 5.00 \\
\hline Wheat bran & 6.50 & 6.50 & 6.50 & 6.50 \\
\hline Feather meal & 5.00 & 5.00 & 5.00 & 5.00 \\
\hline Soybean oil & 1.44 & 1.44 & 4.85 & 4.85 \\
\hline Oyster meal & 0.56 & 0.56 & 0.56 & 0.56 \\
\hline Mineral mix and Vitamin premix* & 0.13 & 0.13 & 0.13 & 0.13 \\
\hline $\mathrm{NaCl}$ & 0.24 & 0.24 & 0.24 & 0.24 \\
\hline L-Threonine & 0.00 & 0.04 & 0.00 & 0.04 \\
\hline L-Lysine $(\mathrm{HCl})$ & 0.32 & 0.35 & 0.32 & 0.35 \\
\hline DL-Methionine & 0.05 & 0.09 & 0.05 & 0.09 \\
\hline Sand & 3.86 & 3.75 & 0,45 & 0,34 \\
\hline \multicolumn{5}{|c|}{ Calculated analysis } \\
\hline Crude protein (\%) & 20.00 & 20.00 & 20.00 & 20.00 \\
\hline Metabolic energy $\mathrm{kcal} / \mathrm{kg}$ & 2,900 & 2,900 & 3,200 & 3,200 \\
\hline Calcium (\%) & 0.90 & 0.90 & 0.90 & 0.90 \\
\hline Available Phosphorus (\%) & 0.35 & 0.35 & 0.35 & 0.35 \\
\hline Total sulfur amino acids (\%) & 0.80 & 0.84 & 0.80 & 0.84 \\
\hline Digestible sulfur amino acids (\%) & 0.63 & 0.67 & 0.63 & 0.67 \\
\hline Lysine total (\%) & 1.06 & 1.09 & 1.06 & 1.09 \\
\hline Lysine digestible (\%) & 0.86 & 0.89 & 0.86 & 0.89 \\
\hline Threonine total (\%) & 0.74 & 0.78 & 0.74 & 0.78 \\
\hline Threonine digestible (\%) & $0 . .58$ & 0.62 & 0.58 & 0.62 \\
\hline $\mathrm{Na}(\%)$ & 0.18 & 0.18 & 0.18 & 0.18 \\
\hline \multicolumn{5}{|c|}{ 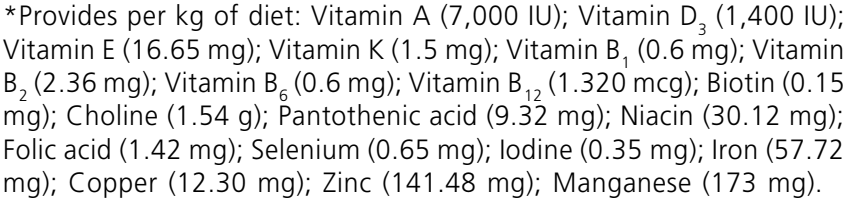 } \\
\hline
\end{tabular}

A completely randomized experimental design was used, in a factorial arrangement $(2 \times 2 \times 2)$. The experimental unit consisted of a cage with 10 birds, there were 5 replicates per treatment and a total of 40 cages. Data were submitted to analysis of variance and Scheffé's test to determine contrasts among treatments.

\section{RESULTS AND DISCUSSION}

The diets formulated on DAA basis, as well as the high-energy diets $(3,200 \mathrm{kcal} / \mathrm{kg})$, resulted in better feed conversion $(p<0.001)$, although no differences were seen for feed intake and weight gain (Table 2). The 
improvement in feed conversion shows that formulation on DAA basis is required for the diets formulated with protein sources that contain amino acids with low digestibility. The wide variation in the composition and the amount of protein and/or amino acids present in animal byproducts is of great concern when using these ingredients. According to Parsons (1992), diet formulation based on total amino acid is equal to diet formulation based on crude energy requirements. Formulation based on DAA is needed in those diets containing protein sources that are not reliable in terms of amino acid digestibility (Maiorka et al., 2004).

The process of pelleting (Table 2 ) promoted a significant increase in feed intake, weight gain, and feed conversion $(p<0.001)$. Such improvements caused by pelleting may be attributed to the combined effects of heat, pressure, and feed humidity. A certain degree of gelatinization occurs, which allows a better use of the nutrients by the birds. The temperature acts on carbohydrates, breaking down amylose and amylopectin granules, and also changes the natural tertiary structure of proteins, improving their digestibility (Moran, 1987). Jensen et al. (1962) reported that the increase in feed density promoted by pelleting resulted in increased growth rate of broilers. These authors observed that birds fed mash diet consumed the same amount of feed three times slower than birds fed pelleted diet.

\begin{tabular}{|c|c|c|c|}
\hline & $\begin{array}{c}\text { Feed } \\
\text { intake }(g)\end{array}$ & $\begin{array}{l}\text { Weight } \\
\text { gain (g) }\end{array}$ & $\begin{array}{c}\text { Feed } \\
\text { conversion }(g / g)\end{array}$ \\
\hline TAA & 3,335 & 1,392 & 2.406 \\
\hline DAA & 3,293 & 1,424 & 2.317 \\
\hline $2,900 \mathrm{kcal} \mathrm{ME} / \mathrm{kg}$ & 3,315 & 1,384 & 2.406 \\
\hline $3,200 \mathrm{kcal} \mathrm{ME} / \mathrm{kg}$ & 3,313 & 1,431 & 2.318 \\
\hline Mash & 3,098 & 1,288 & 2.411 \\
\hline Pellet & 3,530 & 1,527 & 2.312 \\
\hline \multicolumn{4}{|c|}{ Probability } \\
\hline AA & 0.393 & 0.212 & 0.001 \\
\hline Energy & 0.959 & 0.067 & 0.001 \\
\hline Physical form & 0.001 & 0.001 & 0.001 \\
\hline$A A$ * Energy & 0.803 & 0.422 & 0.069 \\
\hline AA * Physical form & 0.279 & 0.158 & 0.226 \\
\hline Energy * Physical form & 0.077 & 0.076 & 0.212 \\
\hline AA * Energy & 0.814 & 0.906 & 0.416 \\
\hline
\end{tabular}

Feed formulation based on DAA did not change weight gain when feed was pelleted. This finding suggests three possibilities. Firstly, feed intake was much higher when pelleted feed was used, and thus the birds ingested the amount of digestible amino acids required for the expression of optimal performance. Secondly, pelleting may have resulted in higher amino acid digestibility due to the action of heat and pressure on protein tertiary structure, enhancing the action of acids and enzymes responsible for their digestion, and therefore increasing amino acid availability (Moran, 1982). Finally, the increase in ME intake promoted by pelleting may have improved the use of ingested amino acids in the protein synthesis possibly due to minimization of the use in energy production.

Animals fed low-energy diets try to obtain adequate energy intake by increasing feed consumption (Rosebrough \& Steele, 1985). In the present study, feed intake was not influenced by dietary energy level. The intake was not higher in birds fed low-energy mash diets probably because the feed geometrical mean diameter $(550 \mathrm{~mm})$ was too small. Since birds have difficulty picking up finely ground diets, feed intake was decreased.

The beak size plays an important role in feed intake regulation, since the birds have difficulty picking up and ingesting particles that are much smaller or much larger than the beak (Moran, 1982). Besides, the saliva in birds is produced in low quantities and has high viscosity, which also contributes to a lower intake of diets with small particle size (Turk, 1982). Thus, a thick paste is formed and adheres to the beak, impairing saliva secretion, picking up of food and swallowing. However, these difficulties were partially compensated when the pelleted diet was fed.

The efficiency of ME utilization (Table 4) was significantly better when birds were fed pelleted diets $(p<0.001)$ formulated on DAA basis $(p<0.001)$ and containing 2,900 kcal ME/kg $(p<0.001)$.

Carcass yield was not significantly influenced by energy level, physical form and diet formulation based on DAA or TAA.

Diets formulated with the higher energy level $(3,200$ $\mathrm{kcal} \mathrm{ME} / \mathrm{kg}$ ) and pelleted diets increased abdominal fat deposition $(p<0.001)$.

\section{REFERENCES}

Baker DH, Han Y. Ideal amino acid profile for chicks during the first three weeks posthatching. Poultry Science 1994; 73:1441-1447.

Donaldson WE. Lipogenesis and body fat in chicks: Effect of calorieprotein ratio and dietary fat. Poultry Science 1985; 64:1199-1204.

Heartland Lysine. True digestibility of essential amino acids for poultry. Chicago, Illinois: NAP, 1995. 


\begin{tabular}{lccc}
\hline Table 3 - Contrasts for feed intake, weight gain and feed conversion. & & \\
Contrasts & Feed intake $\mathbf{( g )}$ & Weight gain (g) & Feed conversion $(\mathbf{g} / \mathbf{g})$ \\
2,900 Pellet x 3,200 Mash & $3,576 \times 3,142$ & $1,529 \times 1,338$ & $2.340 \times 2.325$ \\
DAA, 3,200 Pellet x TAA, 3,200 Pellet & $3,435 \times 3,531$ & $1,514 \times 1,536$ & $2.268 \times 2.299$ \\
DAA, 3,200 Mash x TAA, 3,200 Mash & $3,160 \times 3,124$ & $1,360 \times 1,315$ & $2.325 \times 2.377$ \\
DAA, 2,900 Mash x TAA, 2,900 Mash & $3,048 \times 3,061$ & $1,284 \times 1,194$ & $2.377 \times 2.566$ \\
DAA, 2,900 Pellet x TAA, 2,900 Pellet & $3,527 \times 3,625$ & $1,536 \times 1,523$ & $2.298 \times 2.382$ \\
& Probability & 0.001 & 0.761 \\
2,900 Pellet x 3,200 Mash & 0.001 & 0.667 & 0.542 \\
DAA, 3,200 Pellet x TAA, 3,200 Pellet & 0.336 & 0.378 & 0.312 \\
DAA, 3,200 Mash x TAA, 3,200 Mash & 0.720 & 0.077 & 0.001 \\
DAA, 2,900 Mash x TAA, 2,900 Mash & 0.900 & 0.796 & 0.103 \\
\hline DAA, 2,900 Pellet x TAA, 2,900 Pellet & 0.329 & & \\
\hline
\end{tabular}

Table 4 - Efficiency of ME utilization, carcass yield and abdominal fat deposition of broilers fed diets formulated based on TAA or DAA, with different ME levels (2,900 or 3,200 kcal/kg) and different physical form (pellet or mash) from 21 to 42 days of age.

\begin{tabular}{|c|c|c|c|}
\hline & $\begin{array}{l}\text { Efficiency of ME utilization } \\
\text { (ME/body weight gain) }\end{array}$ & $\begin{array}{l}\text { Carcass } \\
\text { yield }(\%)\end{array}$ & $\begin{array}{l}\text { Abdominal } \\
\text { Fat }(\%)\end{array}$ \\
\hline TAA & 7.33 & 85.99 & 2.25 \\
\hline DAA & 7.06 & 85.87 & 2.14 \\
\hline $2,900 \mathrm{kcal} \mathrm{ME} / \mathrm{kg}$ & 6.98 & 85.57 & 1.83 \\
\hline $3,200 \mathrm{kcal} \mathrm{ME} / \mathrm{kg}$ & 7.74 & 86.29 & 2.57 \\
\hline Mash & 7.34 & 86.09 & 1.88 \\
\hline Pellet & 7.05 & 85.77 & 2.53 \\
\hline \multicolumn{4}{|c|}{ Probability } \\
\hline AA & 0.001 & 0.872 & 0.552 \\
\hline Energy & 0.001 & 0.340 & 0.001 \\
\hline Physical form & 0.001 & 0.665 & 0.001 \\
\hline$A A$ * Energy & 0.094 & 0.588 & 0.779 \\
\hline AA * Physical form & 0.235 & 0.243 & 0.519 \\
\hline Energy * Physical form & 0.292 & 0.642 & 0.359 \\
\hline$A A *$ Energy * Physical form & 0.447 & 0.139 & 0.143 \\
\hline
\end{tabular}

Table $\mathbf{5}$ - Contrasts for efficiency of ME utilization, carcass yield and abdominal fat deposition.

\begin{tabular}{|c|c|c|c|}
\hline Contrasts & $\begin{array}{l}\text { Efficiency of ME utilization } \\
\text { (ME/body weight gain) }\end{array}$ & $\begin{array}{l}\text { Carcass } \\
\text { yield }(\%)\end{array}$ & $\begin{array}{l}\text { Abdominal } \\
\text { fat (\%) }\end{array}$ \\
\hline 2,900 Pellet x 3,200 Mash & $6.79 \times 7.52$ & $85.58 \times 86.66$ & $2.24 \times 2.28$ \\
\hline DAA, 3,200 Pellet $\times$ TAA, 3,200 Pellet & $7.26 \times 7.36$ & $86.22 \times 85.69$ & $2.97 \times 2.64$ \\
\hline DAA, 3,200 Mash x TAA, 3,200 Mash & $7.44 \times 7.61$ & $86.66 \times 86.12$ & $2.10 \times 2.55$ \\
\hline DAA, 2,900 Mash $\times$ TAA, 2,900 Mash & $6.89 \times 7.44$ & $86.30 \times 84.81$ & $1.42 \times 1.43$ \\
\hline \multicolumn{4}{|l|}{ DAA, 2,900 Pellet x TAA, 2,900 Pellet } \\
\hline 2,900 Pellet x 3,200 Mash & 0.001 & 0.327 & 0.738 \\
\hline DAA, 3,200 Pellet $x$ TAA, 3,200 Pellet & 0.674 & 0.726 & 0.368 \\
\hline DAA, 3,200 Mash $\times$ TAA, 3,200 Mash & 0.502 & 0.975 & 0.226 \\
\hline DAA, 2,900 Mash x TAA, 2,900 Mash & 0.095 & 0.329 & 0.982 \\
\hline DAA, 2,900 Pellet $\times$ TAA $, 2,900$ Pellet & 0.387 & 0.959 & 0.499 \\
\hline
\end{tabular}

Jensen LS, Merril LH, Reddy CV. Observations on eating patterns and rate of food passage of birds fed pelleted and unpelleted diets. Poultry Science 1962; 41:1414-1419.

Maiorka A, Dahlke F, Santin E, Kessler AM, Penz Jr AM. Effect of energy levels of diets formulated on total or digestible amino acids basis on broiler performance. Revista Brasileira de Ciência Avícola 2004; 6:87-91.

Moran Jr ET. Comparative nutrition of the fowl and swine. The gastrointestinal system. Guelph, Ontário, Canada: University of Guelph, 1982.

Moran Jr ET. Pelleting affects feed and its consumption. World Poultry 1987; 5:30-31.

National Research Council (NRC). Nutrient Requirements of Poultry. $9^{\text {th }}$ ed. Washington, DC: National Academy Press, 1994, $115 p$.

Parsons CM. Application of the concept of amino acid availability in practical feed formulation. In: Proceeding International Technical Symposium; 1992; Saint Louis, Missouri, EUA. p.45-50

Rosebrough RW, Steele NC. Energy and protein relationships in the broiler. 1. Effect of protein levels and feeding regimens on growth, body composition, and in vitro lipogenesis of broiler chicks. Poultry Science 1985; 64:119-126.

Rostagno HS, Pupa JM, Pack M. Diet formulation for broilers based on total versus digestible amino acids. Journal of Applied Poultry Research 1995; 4:293-299.

Turk DE. The avian gastrointestinal tract and digestion. Poultry Science 1982; 61:1225-1244. 